\title{
O Desastre Ambiental na Barragem de Fundão em Mariana-MG e seus Efeitos Econômicos e Sociais em Minas Gerais e no Espirito Santo
}

\author{
Marília Firmiano $^{1}$ (D) | Guilherme $\operatorname{Irffi}^{2}$ (D) \\ ${ }^{1}$ Mestre em Economia pela Pós-Graduação em Economia CAEN/UFC. E-mail: marilia.firmiano@ipece.ce.gov.br \\ 2 Professor do Depto de Economia Aplicada e do CAEN/UFC. E-mail: irff@@caen.ufc.br
}

\begin{abstract}
RESUMO
O desastre ambiental iniciado em novembro de 2015 em Mariana (MG) provocou uma onda de rejeitos que percorreu os cursos do córrego Santarém e dos Rios Gualaxo Norte e do Carmo até o Rio Doce, seguindo até sua foz em Linhares (ES), deixando parte dos rejeitos no reservatório da hidrelétrica Risoleta Neves e no trecho entre Candonga e Usina Hidrelétrica Baguari. Esta pesquisa analisa a existência de impactos econômicos e sociais desse desastre por meio do modelo de diferenças em diferenças com PSM. Os resultados demonstraram que, no curto prazo, nos municípios localizados próximos à região do desastre, houve impacto negativo sobre as medidas de fluxo escolar (aprovação/reprovação). Também se encontram evidências de impacto negativo sobre PIB dos municípios afetados. Por outro lado, não se verifica diferença significativa sobre o número de internações, entretanto, pelo caráter tóxico da lama, danos à saúde podem tornar-se evidentes no longo prazo.
\end{abstract}

\section{PALAVRAS-CHAVE}

Rio Doce, Mariana, Avaliação de impacto

The Environmental Disaster at the Fundão Dam in Mariana-MG and its Economic and Social Effects in Minas Gerais and Espirito Santo

\begin{abstract}
The environmental disaster that started in November 2015 in Mariana (MG) caused a wave of tailings that ran through the courses of the Santarem stream, the Gualaxo Norte and Carmo rivers to the Doce river, continuing until its mouth in Linhares (ES), leaving part of the tailings in the reservoir of Risoleta Neves Hydroelectric Plant and in the stretch between Candonga and the Baguari Hydroelectric Plant. This research analyzes the economic and social impacts of this disaster through the model of differences in differences with PSM. The results showed that, in the short term, there was a negative impact on school flow measures (pass/fail) and there is also evidence of a negative impact on the GDP of the affected municipalities. On the other hand, there is no significant difference in hospitalizations, however, due to the toxic character of the mud, damage to health can become evident in the long run.
\end{abstract}

\section{KEYWORDS}

Rio Doce, Mariana, Impact evaluation

\section{CLASSIFICAÇÃO JEL}

C15, O1, Q54, R1 1 


\section{Introdução}

O Comitê da Bacia Hidrográfica do Rio Doce (CBH-DOCE) ${ }^{1}$ destaca que a Bacia do Rio Doce possui um contingente populacional estimado em 3,5 milhões de habitantes, distribuídos em 228 municípios, sendo 200 mineiros e 28 capixabas. Também possui rica biodiversidade, com 98\% de sua área inserida no bioma de Mata Atlântica e 2\% no de Cerrado e, ainda, pode ser considerada privilegiada no que se refere à grande disponibilidade de recursos hídricos.

Além disso, a Bacia possui um sistema de drenagem que fornece água para diversos usos, incluindo doméstico, agropecuário, industrial e energético. Sua área de drenagem é de cerca $86.715 \mathrm{~km}^{2}$, dos quais $86 \%$ estão no leste mineiro e $14 \%$ no nordeste do Espírito Santo (ANA, 2016).

Ainda de acordo com a Agência Nacional de Águas (ANA) ${ }^{2}$, essa bacia apresenta um importante potencial hidrelétrico, setor que apresentou uma intensa dinâmica de implantação de novos empreendimentos nas décadas de 2000 e 2010. Dentre os principais reservatórios instalados na bacia estão os de Candonga, Baguari, Aimorés e Mascarenhas localizados no Rio Doce, cuja extensão é de 853 km.

A região possui vocação para a exploração de commodities, principais atividades de exploração mineral aquelas relacionadas à extração de ferro e minério de ferro, atividade antiga e fundamental na história econômica de Minas Gerais (Milanez e Losekann, 2016), feita na região pelas mineradoras Vale e Samarco Mineração, principais produtoras de minério de ferro do país. Além disso, a região contempla Um dos polos de exploração de minério de ferro existentes no Guadrilátero Ferrífero e localizado no município de Mariana é o Complexo Industrial de Germano, pertencente à Mineradora Samarco. A região é grande produtora de minério de ferro, manganês, alumínio, níquel e ouro nativo, entre outros bens minerais, além de pos-suir uma riqueza hídrica e uma paisagem de vales fluviais.

Um dos polos de exploração de minério de ferro existentes no Quadrilátero Ferrífero e localizado no município de Mariana é o Complexo Industrial de Germano, pertencente à Mineradora Samarco. A região é grande produtora de minério de ferro, manganês, alumínio, níquel e ouro nativo, entre outros bens minerais, além de possuir uma riqueza hídrica e uma paisagem de vales fluviais.

O estado de Minas Gerais possui um total de 737 barragens, a maioria delas localizada nas Bacias Hidrográficas do Rio São Francisco, Rio Grande e Rio Doce, compreendendo um quantitativo de barragens de 318, 166 e 131, respectivamente. Do total, cerca de 59,6\% são designadas ao setor de mineração, conforme Inventário de Barragem do Estado de Minas Gerais (FEAM, 2016).

\footnotetext{
${ }^{1}$ Ver: http://www.cbhdoce.org.br/institucional/a-bacia. Acesso em: 17/08/2020.

${ }^{2}$ Ver: https://www.ana.gov.br/sala-de-situacao/rio-doce/rio-doce-saiba-mais. Acesso em: $17 / 08 / 2020$.
} 
Durante os anos de 1986 a 2015, o estado de Minas Gerais registrou nove acidentes ambientais, conforme exibido no Quadro 1, porém nenhum deles atingiu as proporções do desastre ocorrido em novembro de 2015 no município de Mariana, iniciado no dia 5 do supracitado mês, no subdistrito de Bento Rodrigues, que foi caracterizado pela defesa civil como de nível IV, conforme Laudo Técnico do Instituto Brasileiro do Meio Ambiente e dos Recursos Naturais Renováveis, IBAMA (2015), um dos maiores desastres ambientais ocorridos no Brasil, ganhando notoriedade nacional e internacional.

Quadro 1. Registros de rompimentos de barragens e danos no estado de Minas Gerais.

\begin{tabular}{|c|c|}
\hline Ano do desastre & Descrição \\
\hline 1986 & $\begin{array}{l}\text { Barragem de rejeito da Mina de Fernandinho, do Grupo Itaminas, rompe-se em } \\
\text { Itabirito, deixando } 7 \text { vítimas e despejando um volume de rejeitos de } 350.000 \\
\mathrm{~m}^{3} \text {. Ocorrido no dia } 2 \text { de outubro, na mina do Pico de São Luiz, pertencente à } \\
\text { Mineração Brasileira Reunidas (MBR). A lama fluiu por } 10 \mathrm{~km} \text { a jusante. }\end{array}$ \\
\hline 2001 & $\begin{array}{l}\text { No distrito de São Sebastião das Águas (Macacos), em Nova Lima, o rompimento } \\
\text { da barragem operada pela Mineração Rio Verde causou a morte de } 5 \text { vítimas. } \\
\text { O vazamento de } 600.000 \mathrm{~m}^{3} \text { de rejeitos causou o assoreamento de } 6,4 \mathrm{~km} \text { e a } \\
\text { contaminação das águas do córrego Taquara, destruiu cerca de } 80 \text { hectares de } \\
\text { Mata Atlântica e causou o rompimento de uma adutora de água da COPASA. }\end{array}$ \\
\hline 2002 & A barragem da Valle, Forquilha II, rompe-se em Ouro Preto. \\
\hline 2003 & $\begin{array}{l}\text { Em } 29 \text { de março, em Cataguases, na Zona da Mata mineira, a barragem de um } \\
\text { dos reservatórios da Indústria Cataguases de Papel Ltda rompe-se, liberando } \\
\text { no córrego do Cágado e no Rio Paraíba do Sul cerca de } 1,4 \text { bilhão de litros de } \\
\text { lixívia (licor negro), sobra industrial da produção de celulose. O acidente afetou } \\
\text { três estados, deixando } 6.000 \text { mil pessoas sem água. A Fundação Estadual de } \\
\text { Meio Ambiente (FEAM) começa a fiscalizar barragens em Minas. }\end{array}$ \\
\hline 2006 & $\begin{array}{l}\text { No município de Miraí, ocorreu o vazamento de } 1,2 \text { milhões de } \mathrm{m}^{3} \text { de rejei- } \\
\text { tos da mineradora Rio Pomba Cataguases, contaminando córregos, causando } \\
\text { mortandade de peixes e interrompendo fornecimento de água. }\end{array}$ \\
\hline 2007 & $\begin{array}{l}\text { Em janeiro, ocorre um vazamento da barragem de São Francisco Miraí, per- } \\
\text { tencente à mineradora Rio Pomba Cataguases. Foram despejados } 2 \text { milhões } \\
\text { de } \mathrm{m}^{3} \text { de rejeitos, impactando o ribeirão Fubá, o córrego Bom Jardim e o Rio } \\
\text { Muriaé, também afluente do Paraíba do Sul, e inundando os municípios de } \\
\text { Miraí e Muriaé ( } 4 \text { mil pessoas desalojadas e } 1.200 \text { casas atingidas), causando } \\
\text { mortandade de peixes e interrupção no fornecimento de água. }\end{array}$ \\
\hline 2008 & $\begin{array}{l}\text { De responsabilidade da Companhia Siderúrgica Nacional, em Congonhas, o } \\
\text { rompimento da estrutura que ligava o vertedouro à represa da Mina Casa de } \\
\text { Pedra, causa aumento do volume do Rio Maranhão e desaloja } 40 \text { famílias. }\end{array}$ \\
\hline 2014 & $\begin{array}{l}\text { Ruptura em } 10 \text { de setembro da barragem da mineradora Herculano em Ita- } \\
\text { birito. Três operários que realizavam a manutenção no talude de uma barra- } \\
\text { gem de rejeitos desativada morreram soterrados e uma pessoa ficou ferida. O } \\
\text { acidente também resultou na contaminação das águas e no assoreamento de } \\
\text { córregos e rios. }\end{array}$ \\
\hline 2015 & $\begin{array}{l}\text { No dia } 5 \text { de novembro de } 2015 \text {, rompe-se a barragem de Fundão da mineradora } \\
\text { Samarco no município de Mariana, destruindo o subdistrito de Bento Rodri- } \\
\text { gues e ocasionando } 19 \text { mortes. }\end{array}$ \\
\hline 2019 & $\begin{array}{l}\text { No dia } 25 \text { de janeiro de } 2019 \text {, ocorre o rompimento da barragem B1, da Mina } \\
\text { Córrego do Feijão, controlada pela Vale S.A. no município de Brumadinho, } \\
\text { ocasionando em torno de } 250 \text { mortes. }\end{array}$ \\
\hline
\end{tabular}

Fonte: ANA (2016) - Encarte Especial - Bacia do Rio Doce; Milanez et al (2016). 
O rompimento da barragem de Fundão, localizada no Complexo Industrial de Germano, provocou uma onda de rejeitos de minério de ferro e detritos que percorreram os cursos do córrego Santarém e dos rios Gualaxo Norte e do Carmo até alcançar o Rio Doce, seguindo seu curso até a sua foz, localizada em Linhares, litoral do Espírito Santo, deixando parte dos rejeitos acumulados no reservatório da hidrelétrica Risoleta Neves (Candonga) e no trecho entre Candonga e Usina Hidrelétrica Baguari.

Segundo o relatório final da Comissão Extraordinária das Barragens - (ALMG, 2016), com o rompimento da barragem, foram liberados, de imediato, 34 milhões de $\mathrm{m}^{3}$ de rejeitos, volume que percorreu aproximadamente $663 \mathrm{~km}$ até sua chegada ao litoral de Linhares no Espírito Santo, no dia 21 de novembro de 2015. O desastre paralisou as atividades da mineradora Samarco e gerou a interrupção do fornecimento de água e energia elétrica para as comunidades afetadas, dificultando o funcionamento dos setores da indústria e da pesca, bem como a oferta de serviços relacionados à saúde, ao lazer e ao turismo.

A Agência das Nações Unidas United Nations Office for Disaster Risk Reduction UNDRR define os desastres como "uma perturbação grave do funcionamento normal de uma comunidade ou sistema, cujos efeitos nas pessoas, assim como as perdas e danos materiais ou ambientais, superam a capacidade de resposta e a recuperação dessa comunidade" (United Nations Office for Disaster Risk Reduction UNDRR, 2009). Diante disso, optou-se por nomear o ocorrido em Mariana como desastre ambiental.

De acordo com Saito (2008), os níveis de prejuízo dos desastres podem ser calculados como proporção do PIB, classificados como nível um quando o prejuízo é inferior a cinco por cento do PIB, nível dois quando o prejuízo estiver entre 5\% e 10\% do PIB, nível três para o intervalo de dez a trinta por cento e, por último, o nível quatro para aqueles desastres em que o prejuízo supera 30\% do PIB. A avaliação de impacto é um método não usual para dimensionar os efeitos locais de um desastre. O dimensionamento e a classificação de desastres atuam como ferramentas para compreensão, aprimoramento e elaboração de medidas de gestão ao risco, prevenindo novos desastres.

Diante da relevância da região para economia mineira e capixaba, além das proporções do impacto ambiental observado, o trabalho se propõe a avaliar o impacto socioeconômico desse evento. Em outros termos, este estudo busca testar a hipótese de que o desastre ambiental ocorrido em Mariana afetou indicadores econômicos e sociais dos municípios mineiros e capixabas que dependem do Rio Doce e de sua bacia hidrográfica, assim como da atividade mineradora.

Para isto, utilizaram-se indicadores relacionados à educação, à saúde, ao emprego, às exportações e às finanças municipais, realizando o pareamento desses dados a partir de um código de identificação, nesse caso o código do município segundo o IBGE. ${ }^{3}$

\footnotetext{
${ }^{3}$ Ressalta-se nesta pesquisa que os valores monetários relacionados às finanças e exportações foram
} 
Por fim, estruturou-se este trabalho em quatro seções, sendo a primeira esta introdução. A segunda define a estratégia empírica com as descrições dos grupos de tratamento e controle, as fontes e as descrições das variáveis, bem como a metodologia econométrica. A terceira expõe a análise e a discussão dos resultados. Enquanto a última seção apresenta as considerações finais.

\section{Estratégia empirica}

Com a finalidade de verificar os impactos de desastres ambientais na economia, na saúde e em outros aspectos sociais, diversos estudos utilizam modelos que vão desde a aplicação de questionários e entrevistas até métodos como análise de custo-benefício (CBA), MSCE - HM, WATSON, XtraFOOD, IEUBK, de avaliação de impacto do bemestar (MWIA), de equilíbrio geral computável (CGE), de resiliência local do desastre (DROP), Multiregional Impact Assesment (MRIA) e Adaptative Input - output (ARIO).

Alguns estudos analisam o impacto de desastres ambientais. Simonato et al. (2018), utilizando o Modelo DamAge (Dynamic Applied Minning General Equilibrium Model), buscaram fazer a projeção dos impactos econômicos regionais do desastre em Minas Gerais. De acordo com os autores, os resultados indicaram que o período adotado de cinco anos mostra-se insuficiente para a retomada de níveis de produção, consumo das famílias, emprego, investimento e comércio estabelecidos antes do evento, mesmo com a plena retomada, em Mariana, das atividades de mineração a partir de 2018.

Castro e Almeida (2019) avaliam o impacto do desastre no desempenho econômico de MG e ES, utilizando o método de controle sintético, e encontram resultados que a produção industrial geral, no ES, teve redução de 18,22\%, ao passo que para MG não houve impacto significativo. No tocante à produção extrativa mineral, ambos os estados apresentaram diminuição significativa com 25,01\% em ES e 15,58\% em MG. Com mesmo objetivo, Niquito et al. (2019) fazem uma análise dos impactos econômicos de curto prazo do rompimento da barragem de Fundão sobre a produção e o emprego. Utilizando modelos de diferenças em diferenças com efeitos fixos que acomodam a possibilidade de defasagem espacial. Os resultados evidenciam efeitos negativos sobre o PIB um impacto negativo sobre o PIB $(-6,94 \%)$, sobre o valor adicionado industrial $(-18,66 \%)$ e sobre o emprego industrial (-372 empregos formais, em média).

Sales e Rocha (2020) usam o modelo de diferenças em diferenças (DD) para avaliar os efeitos do desastre de Mariana em indicadores econômicos e de saúde. Quanto aos resultados, em relação à economia local, os autores destacam um impacto negativo sobre o PIB municipal (-5,4\%), impulsionado por uma redução na produção do setor manufatureiro (-13,8\%), e sobre o valor da produção da aquicultura (-5,9\%). Já em relação à saúde, o impacto foi positivo na mortalidade infantil neonatal (+9,3\%) e em

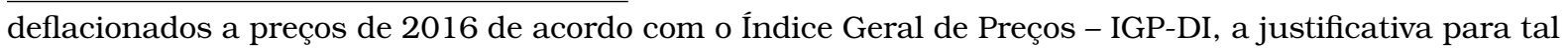
indice se dá pelo fato que esse reflete o comportamento econômico no Brasil. 
internações por doenças de pele $(+12 \%)$.

Outras pesquisas buscaram verificar os impactos na saúde do evento ocorrido em MG, a exemplo de Carrillo et al. (2020), que exploraram a exposição in utero ao desastre a partir do modelo de DD e observaram tanto uma redução do peso ao nascer (em média, 23 gramas) como um aumento da mortalidade infantil. Além disso, os efeitos tornam-se mais adversos para bebês nascidos de mães solteiras, com menor escolaridade e não casadas. Os resultados ainda indicam que a regulamentação ambiental mal aplicada pode ter impactos de bem-estar de longo prazo nas comunidades locais. Ao avaliarem como o desastre afetou a saúde de recém nascidos expostos durante a gravidez, Mrejen et al. (2020) verificam que houve uma redução no tempo de gestações (1,86 dias mais curtas) e um aumento de 2,6 pontos percentuais na incidência de parto prematuro quando a exposição ocorreu em cidades diretamente afetadas.

Desta forma, assim como Niquito et al. (2019) e Sales e Rocha (2020), utilizam-se dados em painel para os municípios, entretanto, difere-se a partir do uso do método ao combinar o modelo DD com propensity score matching (PSM), para avaliar o impacto do desastre ambiental ocorrido em Mariana sobre os indicadores econômicos e sociais dos municípios mineiros e capixabas.

\subsection{A Identificação dos Grupos de Tratamento e Controle}

Para avaliar os efeitos sociais e econômicos provocados pelo rompimento da barragem de Fundão no município de Mariana - MG, adotaram-se quatro estratégias para identificação dos municípios afetados pelo desastre, denominados como grupos de tratamento, apresentados no Quadro 2.

A primeira estratégia leva em consideração os municípios mineiros e capixabas interceptados pelo Rio Doce. A segunda refere-se aos municípios limítrofes aos interceptados pelo Rio Doce. Espera-se que tais municípios, mesmo relativamente distantes do rio, sofram alguma externalidade negativa do desastre. Já a terceira estratégia utiliza como parâmetro a classificação da $\mathrm{ANA}^{4}$ quanto aos municípios afetados pelo desastre. E, por fim, são considerados somente os municípios pertencentes ao Quadrilátero Ferrífero mineiro. Os grupos são exibidos na Figura 1.

\footnotetext{
${ }^{4}$ Agência Nacional de Águas. Monitoramento da Qualidade da Água. Monitoramento do Rio Doce. Disponivel em:

http://portal1.snirh.gov.br/ana/apps/webappviewer/index.html?id=a3f5de1cbd004c86bee8e86f2444d1e5. Acesso em: 6 jun. 2018. Agência Nacional de Águas. Programa de Monitoramento Quali-Quantitativo Sistemático de Água e Sedimentos (PMQGS). Disponivel em: http://www2.ana.gov.br/Paginas/Riodoce/default.aspx. Acesso em: 7 jun. 2018.
} 


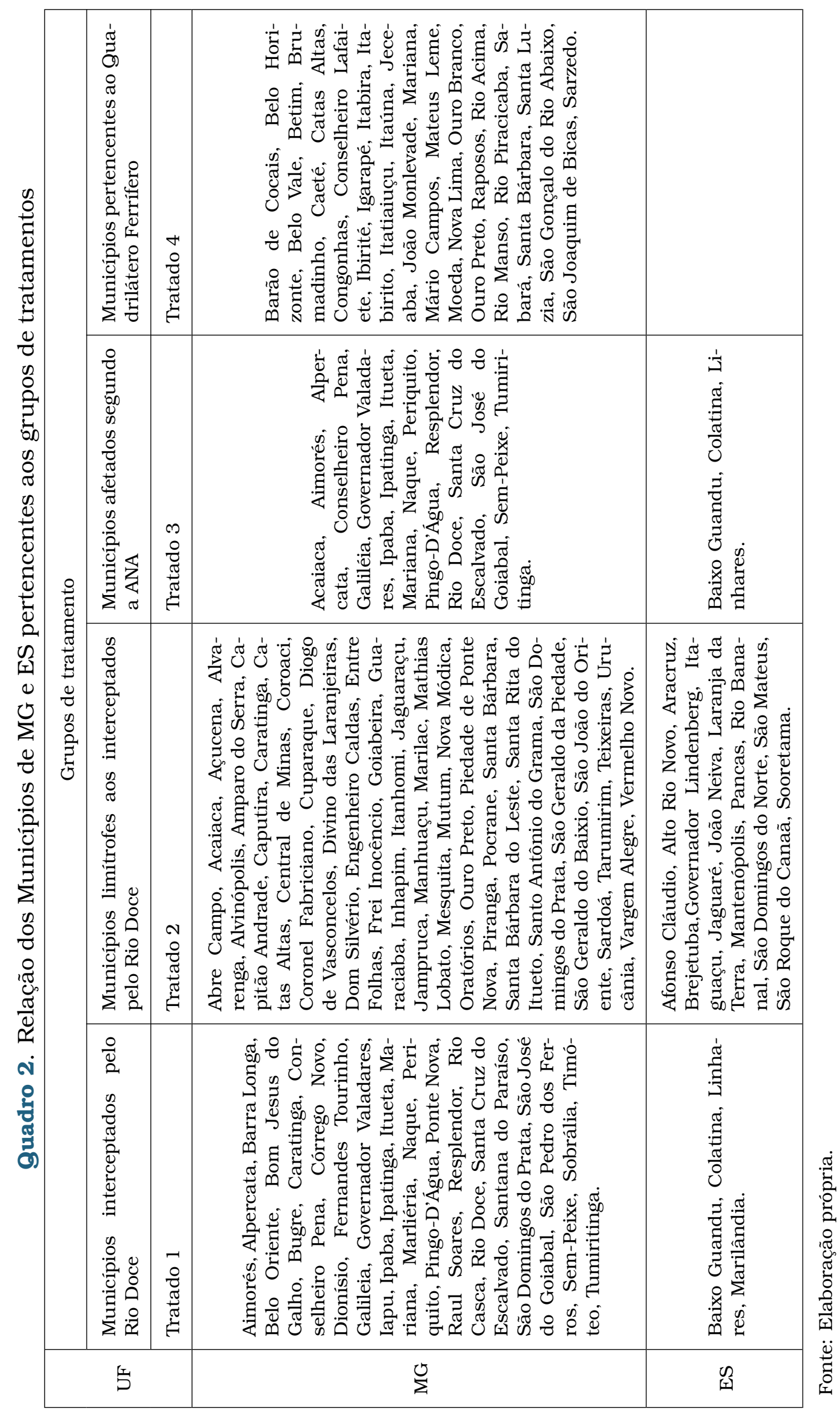


Figura 1. Grupos de Tratamento para identificar os efeitos do rompimento da barragem de Fundão em Mariana - MG.



Tratado 1: Municípios interceptados pelo Rio Doce

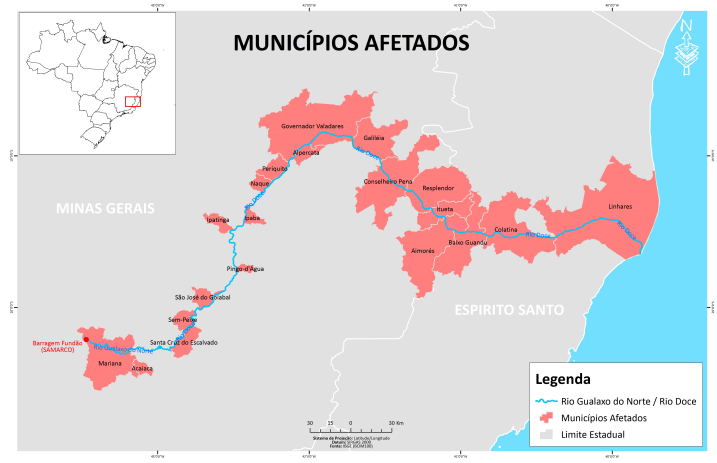

Tratado 3: Municípios Afetados pelo Rio

Fonte: Elaboração própria.

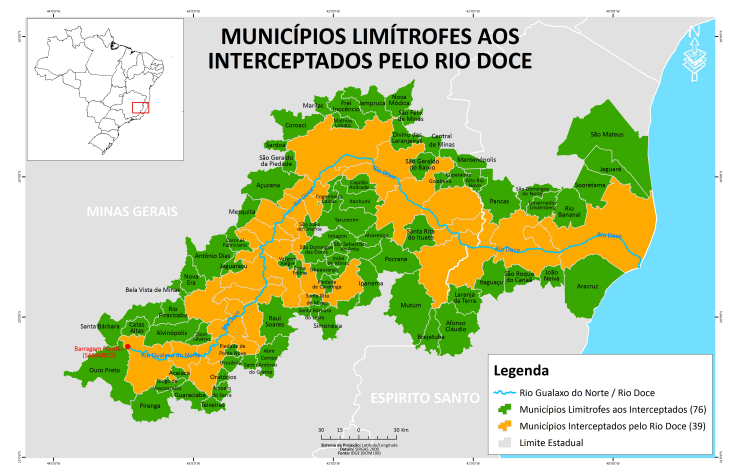

Tratado 2: Municípios limítrofes aos interceptados pelo Rio

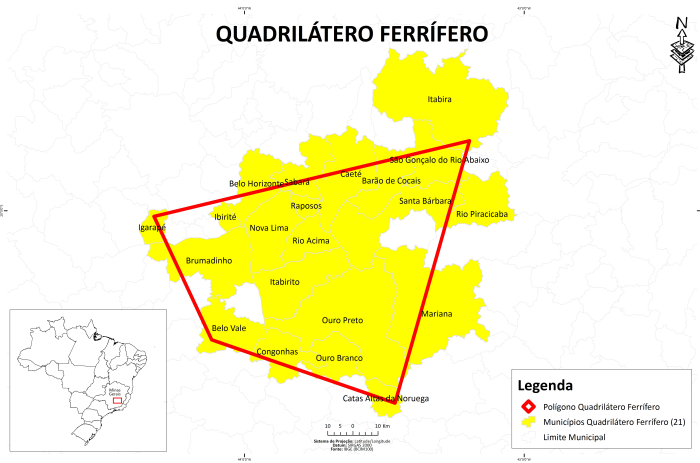

Tratado 4: Municípios pertencentes ao Quadrilátero Ferrífero

A partir destas quatro estratégias, são avaliados os resultados e impactos do desastre ambiental causado pelo rompimento da barragem Fundão, e busca-se entender a dimensão dos efeitos e a extensão territorial do desastre. Para isto, faz-se necessário estimar o contrafactual para computar a diferença, caso esses municípios não tivessem sido atingidos pelo desastre. Para ter esses resultados, é preciso utilizar grupos de controle que representem os municípios afetados, direta e indiretamente, na ausência do desastre. Utiliza-se, então, a metodologia de pareamento para formação desses grupos, a partir das características observáveis.

\subsection{Os Indicadores de Resultados e Impactos}

Nesta pesquisa, foram coletados dados socioeconômicos relacionados aos 5.565 municípios brasileiros. Para que a base seja identificada por município, faz-se necessário eleger um identificador comum para todos os dados para fazer um merge, a partir do código do município segundo o IBGE, para emparelhar e compatibilizar os dados municipais. Por fim, destaca-se que os dados analisados compreendem o período de 2010 a 2016. As variáveis são sumarizadas no Quadro 3. 


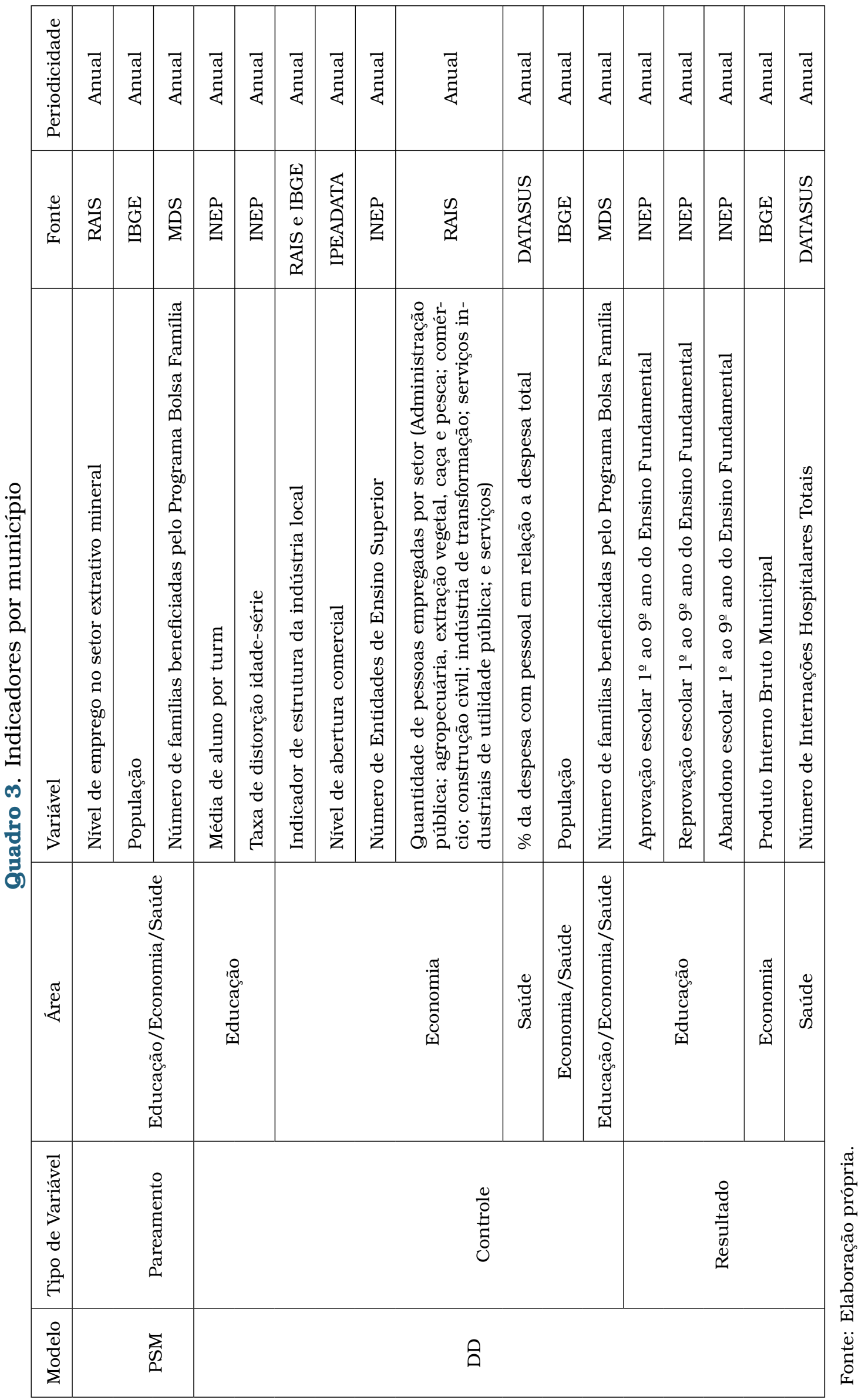


No tocante às informações atreladas à educação, foram selecionadas variáveis associadas às taxas de rendimento escolar (aprovação, reprovação e abandono escolar), consideradas como variáveis de resultado, além da taxa de distorção idade-série, média de aluno por turma e número de Entidades de Ensino Superior, extraídas no Instituto Nacional de Estudos e Pesquisas Educacionais Anísio Teixeira - INEP, que compõem as variáveis de controle. No tocante à saúde, foram selecionados dados relacionados ao número de internações, como variável de resultado, e percentual da despesa com pessoal em relação a despesa total, como variável de controle, de acordo com DATASUS/ Ministério da Saúde - MS. Para proxies para dados relacionados à economia, optou-se pelo PIB municipal como variável de resultado, a partir das informações coletadas pelo IBGE.

Em relação às variáveis de controle, utiliza-se o indicador de estrutura da indústria local $^{5}$ e de abertura comercial ${ }^{6}$ extraídos no portal IPEADATA, além dos dados do nível de emprego por setor (extrativo mineral, indústria de transformação, serviços industriais de utilidade pública, construção civil, comércio, serviços, administração pública, agropecuária, extração vegetal, caça e pesca) coletados na Relação Anual de Informações Sociais - RAIS fornecida pelo Ministério do Trabalho e Emprego MTE. Além dos dados supracitados, ainda se utilizam a população e o quantitativo de famílias beneficiadas pelo Bolsa Família, dados fornecidos, respectivamente, pelo IBGE e Ministério do Desenvolvimento Social - MDS.

\subsection{O Método de Diferenças em Diferenças}

De acordo com Menezes Filho et al. (2017), o método DD é aplicável no contexto denominado experimento natural (ou quase experimento), uma situação na qual a ocorrência de um evento fortuito - ou em larga medida imprevisto - permite formar grupos de tratamento e controle parecidos em diversos aspectos. De acordo com o autor, esses eventos podem ter origem em mudanças que ocorrem na própria natureza, como terremotos e furacões.

As circunstâncias de experimento natural não garantem que o grupo de controle seja uma boa representação do grupo tratado, no entanto o método de DD procura mitigar essa situação, levando em consideração as diferenças de características preexistentes entre tratados e controles. Uma hipótese do método DD é que a trajetória temporal da variável de resultado para o grupo de controle seja uma boa proxy para o que ocorreria com o grupo tratado caso esse não fosse afetado pelo tratamento.

Outra hipótese relevante para a adequação do modelo é que a composição tanto do grupo de controle como do de tratamento não se alterem de forma significativa entre os períodos anterior e posterior ao evento. Assim, o método é capaz de lidar com o viés de seleção associado a características não observáveis dos indivíduos e que são invariantes no tempo. O modelo utilizado nesta pesquisa pode ser descrito da seguinte

\footnotetext{
${ }^{5}$ Calculado a partir da razão entre o número de empregos (indústria e serviço) e a população total.

${ }^{6}$ Calculado a partir da diferença entre exportação e importação.
} 
forma: $\mathrm{T}=1,0$ trata se o município foi afetado ou não pelo desastre de Mariana - MG, enquanto $\mathrm{t}=1,0$ representa os períodos posterior ou anterior ao desastre. Sendo o estimador $\beta_{D D}$ calculado da seguinte forma:

$$
\beta_{D D}=E\left[Y_{i} \mid T_{i}=1, t=1\right]-E\left[Y_{i} \mid T_{i}=0, t=1\right]-E\left[Y_{i} \mid T_{i}=1, t=0\right]-E\left[Y_{i} \mid T_{i}=0, t=0\right]
$$

Tal estimador captura o efeito médio do desastre sobre os municípios que foram afetados pelo desastre de Mariana. O modelo de regressão pode ser descrito como:

$$
\begin{array}{r}
Y_{i t}=\alpha+\gamma \text { Tratado }_{i}+\rho \text { Tempo }_{t}+\beta\left(\text { Tratado }^{*} \text { Tempo }_{i}\right)+X_{i}+\text { tendano }+ \text { tendano }^{2}+ \\
M G+E S+\varepsilon_{i t}
\end{array}
$$

Em que:

- $M G=$ Variável binária, 1 se o município pertence ao estado de Minas Gerais e 0 caso contrário.

- $E S$ = Variável binária, 1 se o município pertence ao estado do Espírito Santo e 0 caso contrário.

- Tendano = tendência linear para captar a evolução temporal, variando de 1 a 7 , para 2010 a 2016.

- Tendano $^{2}=$ tendência quadrática.

- Tratado $_{i}=$ variável binária, 1 se o município é tratado (afetado pelo desastre) e 0 , caso contrário.

- Tempo $_{t}=$ variável binária que será 1 no período depois do desastre e 0 caso contrário.

- $\varepsilon_{i t}=$ Erro aleatório, cuja média é zero.

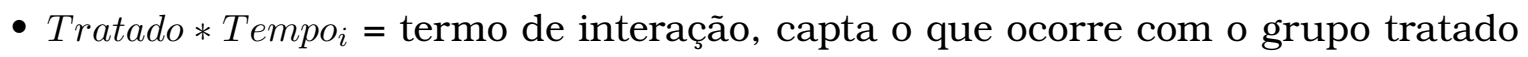
após o desastre.

- $X_{i}=$ variáveis de controle, cada variável de resposta recebe um número específico de covariáveis.

Vale ressaltar que $\rho$ impõe que a variável de resultado, na ausência da intervenção, varie entre os períodos da mesma forma tanto para tratados quanto para controles, ou seja, impõe a restrição de tendência temporal similar. Cabe ainda destacar que o DD com mais de dois períodos permite que o efeito da heterogeneidade no modelo. Uma desvantagem desse método está na dificuldade em lidar com casos em que alguma mudança temporal em um fator não observado afete a decisão dos agentes quanto a participar do tratamento. No caso deste estudo, estamos lidando com o fato de o município ser afetado ou não pelo desastre, logo um fator não observado 
poderia ser a possibilidade de certos indivíduos preverem o acidente e se mudarem antecipadamente do município antes do desastre, algo improvável, porém possível.

\subsection{O Método de Propensity Score Matching (PSM)}

A hipótese principal desse método consiste em que o vetor de características observáveis contenha as informações sobre o resultado potencial na ausência ou presença do tratamento, que afetam a decisão de o indivíduo participar ou não do tratamento. O método de pareamento busca agrupar um controle para um grupo de tratamento, desta forma torna-se necessária a hipótese de sobreposição, da seguinte forma:

$$
0<\operatorname{Pr}\left[T_{i}=1 \mid X_{i}\right]<1
$$

Rosenbaum e Rubin (1983) aprimoraram o método, considerando que, em vez de haver um vetor de características observáveis, pode-se parear os grupos por meio de uma função de probabilidade dessas, denominado escore de propensão. Esse escore é estimado através de modelos paramétricos como o Logit, da seguinte forma:

$$
\operatorname{Pr}\left[T_{i}=1 \mid X_{i}=x\right]=\frac{\exp (x \beta)}{1+\exp (x \beta)}
$$

Uma crítica para tal método consiste no fato de que não só as características observáveis afetam a decisão em participar do tratamento, mas também as não observáveis influenciam tal decisão, dessa forma a presença dessa última pode incorrer em viés de seleção.

\subsection{O Método de Diferenças em Diferenças com Pareamento}

O PSM visa corrigir o viés de seleção e o viés associado às características observáveis que afetam os municípios tratados. O modelo DD contribui para mitigar o viés associado às características observáveis e não observáveis (desde que essas sejam constantes no tempo). Em função disso, ao combinar o modelo DD com PSM, como proposto por Heckman et al. (1997), busca-se estimar a partir de uma subamostra o efeito causal do desastre ambiental provocado pelo rompimento da barragem e o despejo de rejeito de minério nos leitos do Rio Doce sobre indicadores sociais (educacionais e de saúde) e econômicos.

\section{Análise e Discussão dos Resultados}

Com a finalidade de avaliar o impacto nos municípios afetados pelo desastre ambiental de Mariana, em termos de efeitos, optou-se por apresentar os resultados DD com PSM a partir de indicadores nas áreas de educação, saúde e economia. 
Para estimação do pareamento, utilizou-se um modelo Logit com variáveis de nível de emprego no setor extrativo mineral (proxy para atividade nesse setor), população e número de famílias beneficiárias do Programa Bolsa Família (PBF), o que se justifica pelo desastre estar diretamente relacionado à atividade de mineração. Ademais, o tamanho da população do município e o número de famílias beneficiadas pelo PBF tornam-se variáveis elegiveis, tendo em vista que um explicita o quantitativo populacional e o outro indica o perfil socioeconômico do município, dado que o método de estimação busca um contrafactual, controlando por características observáveis e independentes do desastre. Vale ressaltar que pelos pesos foi realizada por meio do modelo Kernel (0.01) com base na região de suporte comum para as variáveis de resultados, como se observa nos Gráficos 1 a 20, em anexo.

Após a realização do pareamento, estimou-se o modelo de DD para variáveis na área de educação, saúde e economia, utilizando como variáveis de resultado taxas de rendimento escolar (aprovação, reprovação e abandono escolar), número de internações hospitalares e PIB municipal, respectivamente. Cabe destacar que, para estimação em cada área, foram utilizados conjuntos de variáveis de controle diferentes, conforme exposto na subseção 2.2 e no Guadro 3.

\subsection{Análise sobre os Indicadores Educacionais}

Para avaliar se o desastre ambiental repercutiu nos indicadores educacionais, utilizam-se medidas de fluxo escolar, como as taxas de abandono, aprovação e reprovação dos anos iniciais do ensino fundamental.

Em relação aos resultados, verifica-se que os municípios limítrofes ao interceptados pelo Rio Doce (grupo tratado 2) são impactados pelo rompimento da barragem. Em outros termos, pode-se dizer que existe efeito transbordamento sobre esses municípios vizinhos aos diretamente afetados pelo desastre. O desastre reduziu (aumentou) a taxa de aprovação (reprovação) dos anos iniciais ( $1^{\circ}$ ao $5^{\circ}$ ano) do ensino fundamental, como se observa na Tabela 1. Em função desses resultados, faz-se necessária uma política educacional de correção de fluxo para mitigar a distorção idade-série, dado que esse efeito pode gerar maiores custos educacionais como programas de Jovens e Adultos. Além disso, como os anos iniciais do ensino fundamental podem ser considerados como um alicerce para o desempenho educacional dos anos finais, no ensino médio e universitário e, ainda, sobre resultados no mercado de trabalho, devem-se buscar ações e programas que possam contribuir para a recuperação da aprendizagem e a correção de fluxo. 


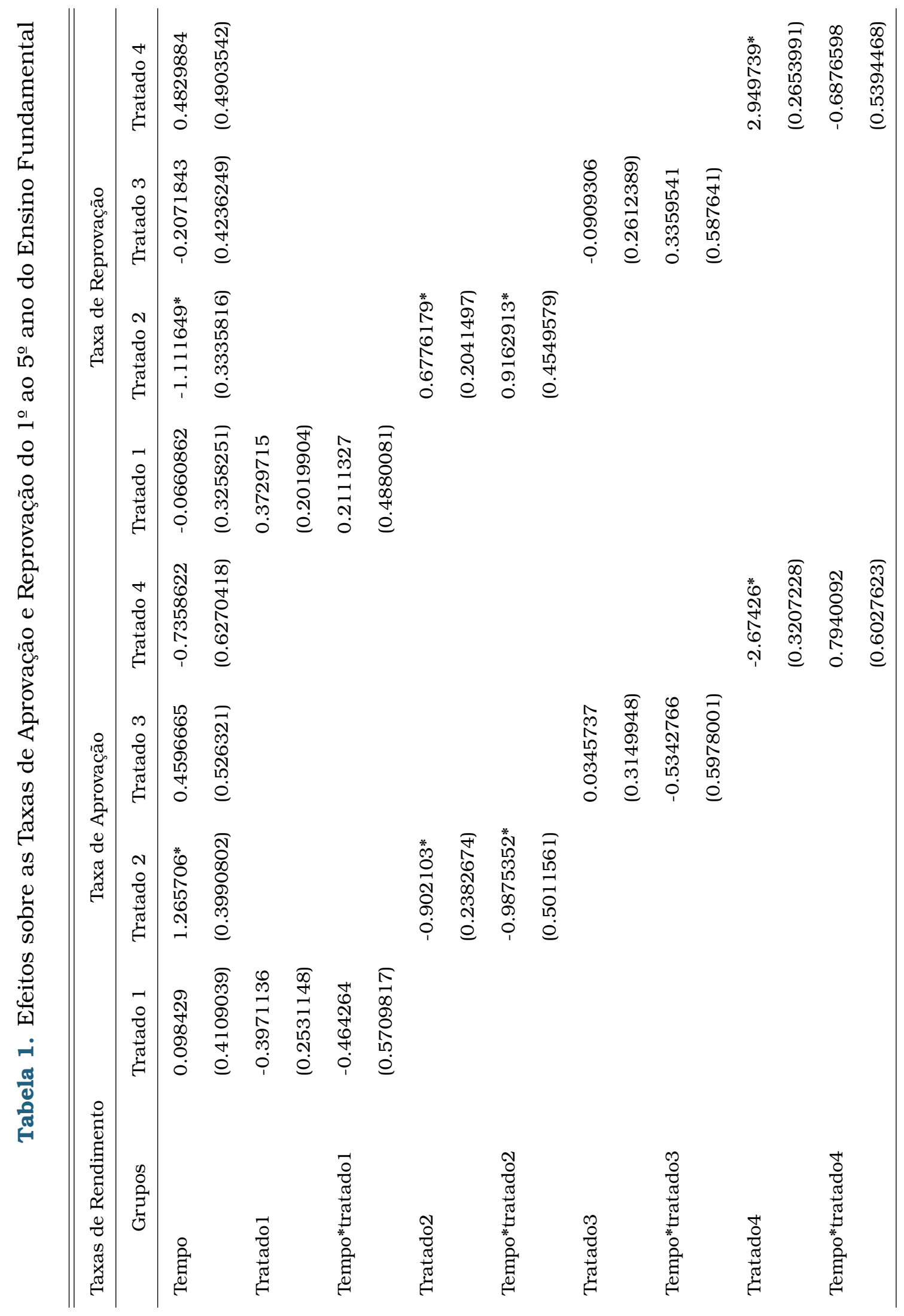




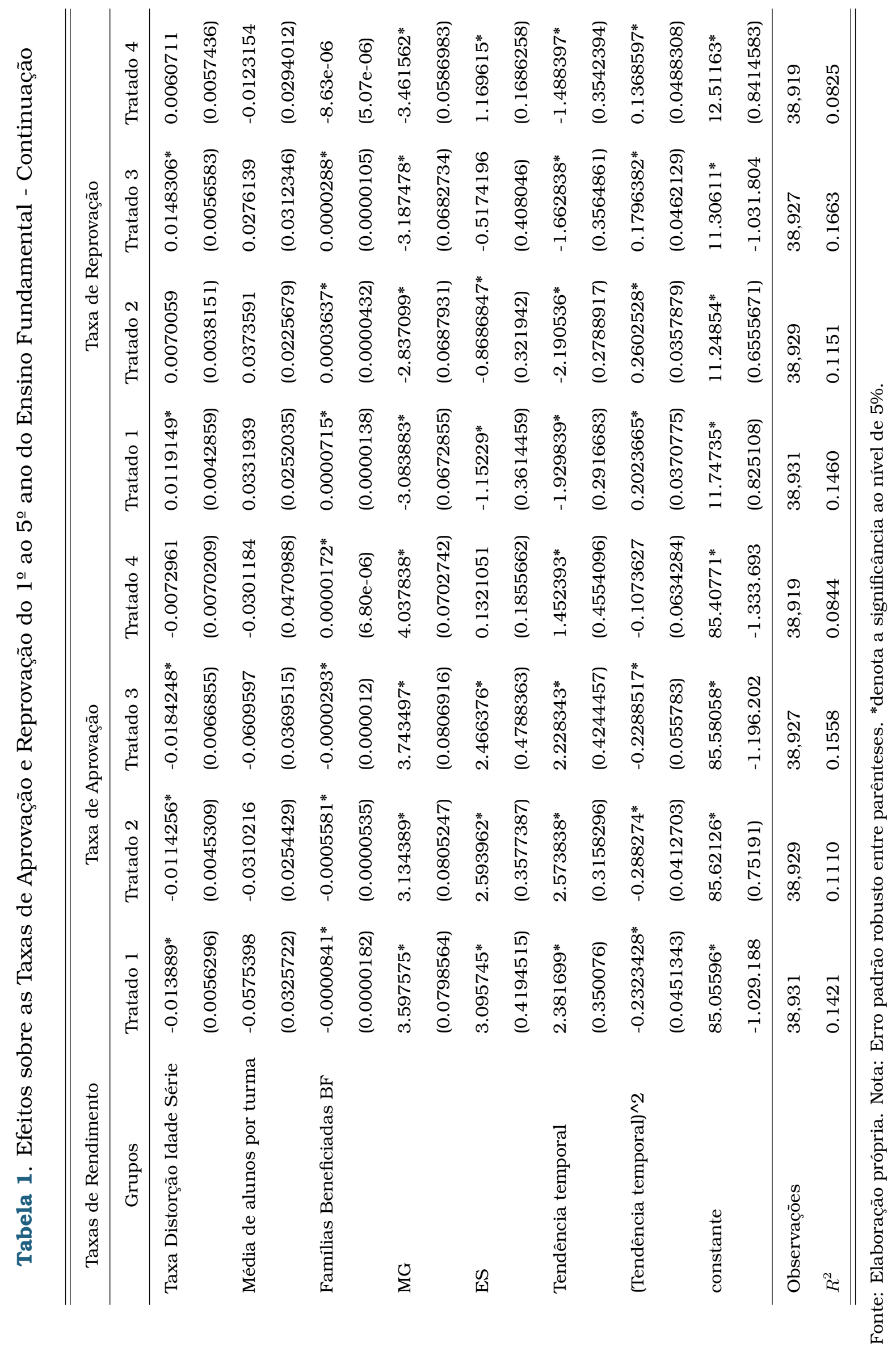


Em relação à taxa de abandono, Tabela 2, não se observa efeito diferença entre os municípios afetados, direta ou indiretamente, pelo rompimento da barragem de Fundão. Vale ressaltar que, após o desastre, a Fundação Renova disponibilizou escolas temporárias para receber os estudantes diretamente afetados, o que pode ter relação com esse resultado. ${ }^{7}$

\subsection{Análise sobre os Indicadores de Saúde}

Ao analisar os efeitos sobre o indicador de saúde, número de internações, não se observa diferença significativa entre os grupos de tratamento e controle. Sendo assim, ao menos no curto prazo, o desastre ambiental não teve efeitos sobre o número de internações, resultado que pode ser visto na Tabela 3. No entanto, os impactos do desastre natural sobre a saúde no curto prazo podem ter ocorrido de forma mais intensa caso se leve em consideração que nem todos os indivíduos afetados por enfermidades relacionadas ao desastre são internados. Em tais casos, mesmo sem se ter a ocorrência de internações, ainda é possível que tais adversidades afetem os indivíduos de forma significativa, podendo, por exemplo, ocasionar perdas de rendimento dos trabalhadores ou dos estudantes. É possivel ainda que o impacto do desastre seja verificado no longo e não no curto prazo, principalmente por doenças relacionadas à contaminação por metal pesado como manganês e ferro, observado em material coletado no Rio Doce, como apontado por Torres et al. (2017) e Queiroz et al. (2021).

Em adição, Sales e Rocha (2020), a partir dos microdados do Sistema de Hospitalização (DataSus / SIH) e coleta de informações para o período 2010-2017 por mês de internação e principal causa - com base no CID- $10^{8}$, após o cálculo da taxa de internação e análise por doenças específicas, especificamente até junho de 2017, verificaram um impacto positivo de 12\%, em média, nas internações por doenças de pele, significativa a 10\%. Diferente desse artigo, o período utilizado para analisar o número de internações é de 2010-2016 e, ainda, cabe ressaltar que não foram consideradas doenças específicas.

De acordo com Lacaz et al. (2017), os agravos e danos de vidas humanas decorrentes da tragédia da barragem de rejeitos de Fundão/Samarco foi de 256 feridos, 280 enfermos e 18 mortos. Os autores ressalta a preocupação com a saúde psicológica do indivíduo atingido pelo desastre, algo que corrobora os efeitos de longo prazo do desastre.

\footnotetext{
${ }^{7}$ Para mais detalhes, ver: https://www.bbc.com/portuguese/brasil-41798753 (Acesso em: 20/08/2020); https://www.em.com.br/app/noticia/gerais/2016/02/17/interna_gerais,734845/alunosafetados-por-estouro-de-barragem-em-minas-enfrentam-obstaculos.shtml (Acesso em: 20/08/2020); https://exame.com/brasil/pericia-lista-problemas-em-escolas-de-area-afetada-por-lama-da-samarco/ (Acesso em: 20/08/2020).

${ }^{8}$ A Classificação Internacional de Doenças (CID-10), publicada pela Organização Mundial de Saúde (OMS), visa padronizar a codificação de doenças e outros problemas relacionados à saúde.
} 
Tabela 2. Efeitos sobre a Taxa de Abandono do $1^{\circ}$ ao $5^{\circ}$ ano do Ensino Fundamental

\begin{tabular}{|c|c|c|c|c|}
\hline Abandono Ens. Fundamental & Tratado 1 & Tratado 2 & Tratado 3 & Tratado 4 \\
\hline \multirow[t]{2}{*}{ Tempo } & -0.032343 & -0.1540571 & -0.2524826 & 0.2528739 \\
\hline & $(0.158175)$ & $(0.1295956)$ & $(0.2076101)$ & $(0.2440383)$ \\
\hline \multirow[t]{2}{*}{ Tratado 1} & 0.0241423 & & & \\
\hline & $(0.1020294)$ & & & \\
\hline \multirow[t]{2}{*}{ Tempo*tratado 1} & 0.253131 & & & \\
\hline & $(0.2367563)$ & & & \\
\hline \multirow[t]{2}{*}{ Tratado2 } & & $0.2244851^{*}$ & & \\
\hline & & $(0.0804663)$ & & \\
\hline \multirow[t]{2}{*}{ Tempo*tratado2 } & & 0.0712436 & & \\
\hline & & $(0.1394886)$ & & \\
\hline \multirow[t]{2}{*}{ Tratado3 } & & & 0.0563569 & \\
\hline & & & $(0.13292)$ & \\
\hline \multirow[t]{2}{*}{ Tempo*tratado3 } & & & 0.1983226 & \\
\hline & & & $(0.2276906)$ & \\
\hline \multirow[t]{2}{*}{ Tratado4 } & & & & $-0.2754793^{*}$ \\
\hline & & & & $(0.1117256)$ \\
\hline \multirow[t]{2}{*}{ Tempo*tratado4 } & & & & -0.1063489 \\
\hline & & & & $(0.1801308)$ \\
\hline \multirow[t]{2}{*}{ Taxa Distorção Idade Série } & 0.0019741 & $0.0044197^{*}$ & 0.0035942 & 0.0012251 \\
\hline & $(0.0022576)$ & $(0.0015221)$ & $(0.00248)$ & $(0.0023544)$ \\
\hline \multirow[t]{2}{*}{ Média de alunos por turma } & 0.0243459 & -0.0063376 & $0.0333458 *$ & 0.0424339 \\
\hline & $(0.0127051)$ & $(0.008051)$ & $(0.0139599)$ & $(0.0286437)$ \\
\hline \multirow[t]{2}{*}{ Famílias Beneficiadas BF } & 0.0000125 & $0.0001944^{*}$ & $4.92 \mathrm{e}-07$ & $-8.61 \mathrm{e}-06^{*}$ \\
\hline & $(6.94 \mathrm{e}-06)$ & $(0.0000197)$ & $(3.38 \mathrm{e}-06)$ & $(3.21 \mathrm{e}-06)$ \\
\hline \multirow[t]{2}{*}{ MG } & $-0.5136925^{*}$ & $-0.2972899 *$ & $-0.556019^{*}$ & $-0.5762759 *$ \\
\hline & (0.025819) & $(0.0259968)$ & (0.0266809) & $(0.0251362)$ \\
\hline \multirow[t]{2}{*}{$\mathrm{ES}$} & $-1.943454^{*}$ & $-1.725278^{*}$ & $-1.948956^{*}$ & $-1.30172^{*}$ \\
\hline & $(0.1152371)$ & (0.0964656) & (0.1509529) & $(0.0377377)$ \\
\hline \multirow[t]{2}{*}{ Tendência temporal } & $-0.4518601^{*}$ & $-0.3833025^{*}$ & $-0.5655053^{*}$ & 0.0360041 \\
\hline & $(0.1374586)$ & $(0.0955577)$ & $(0.1916654)$ & $(0.2043246)$ \\
\hline \multirow[t]{2}{*}{ (Tendência temporal)^^2 } & 0.0299763 & $0.0280212^{*}$ & $0.0492135^{*}$ & -0.029497 \\
\hline & $(0.0177909)$ & $(0.0128576)$ & $(0.024539)$ & $(0.0281705)$ \\
\hline \multirow[t]{2}{*}{ constante } & $3.19669^{*}$ & $3.130204 *$ & $3.113305^{*}$ & $2.080661^{*}$ \\
\hline & (0.3720205) & $(0.2406976)$ & $(0.4426457)$ & (0.8019697) \\
\hline Observações & 38,931 & 38,929 & 38,927 & 38,919 \\
\hline$R^{2}$ & 0.0912 & 0.1169 & 0.1036 & 0.0673 \\
\hline
\end{tabular}

Fonte: Elaboração própria. Nota: Erro padrão robusto entre parênteses. ${ }^{* *}$ denota a significância ao nivel de $5 \%$. 
Tabela 3. Efeitos sobre o número de internações

\begin{tabular}{|c|c|c|c|c|}
\hline Internações & Tratado 1 & Tratado 2 & Tratado 3 & Tratado 4 \\
\hline \multirow[t]{2}{*}{ Tempo } & -1.582 .009 & -4.444 .102 & -233.789 & 9.482 .194 \\
\hline & -1.267 .814 & -6.132 .464 & -1.774 .139 & -8.689 .837 \\
\hline \multirow{2}{*}{ Tratadol } & $-249.3556^{*}$ & & & \\
\hline & -710.529 & & & \\
\hline \multirow[t]{2}{*}{ Tempo*tratado 1} & 2.557 .177 & & & \\
\hline & -1.620 .592 & & & \\
\hline \multirow[t]{2}{*}{ Tratado2 } & & $-223.5608^{*}$ & & \\
\hline & & -2.616 .609 & & \\
\hline \multirow[t]{2}{*}{ Tempo*tratado2 } & & 143.129 & & \\
\hline & & -9.964 .704 & & \\
\hline \multirow[t]{2}{*}{ Tratado3 } & & & $-306.7045^{*}$ & \\
\hline & & & -1.375 .728 & \\
\hline \multirow[t]{2}{*}{ Tempo*tratado3 } & & & 3.692 .478 & \\
\hline & & & -2.198 .174 & \\
\hline \multirow[t]{2}{*}{ Tratado4 } & & & & 298.082 \\
\hline & & & & -455.713 \\
\hline \multirow[t]{2}{*}{ Tempo*tratado4 } & & & & 4.701 .202 \\
\hline & & & & -8.393 .101 \\
\hline \multirow[t]{2}{*}{ Famílias Beneficiadas BF } & $1.02336^{*}$ & $0.7949981^{*}$ & $1.145696^{*}$ & $1.650113^{*}$ \\
\hline & $(0.0302869)$ & $(0.0172078)$ & $(0.0787511)$ & $(0.4054484)$ \\
\hline \multirow[t]{2}{*}{ \% Despesa Pessoal/Despesa Total } & $-10.82971^{*}$ & $-6.755242^{*}$ & $-18.65507^{*}$ & $-47.89275^{*}$ \\
\hline & -1.731 .934 & -1.001 .703 & -3.317 .616 & -1.309 .881 \\
\hline \multirow[t]{2}{*}{$\mathrm{MG}$} & $516.22^{*}$ & $161.2443^{*}$ & $767.1057^{*}$ & $989.7905^{*}$ \\
\hline & -5.396 .834 & -1.463 .628 & -985.158 & -3.673 .732 \\
\hline \multirow[t]{2}{*}{ ES } & $1129.333^{*}$ & $283.9145^{*}$ & $1112.916^{*}$ & $904.2105^{*}$ \\
\hline & -1.429 .379 & -6.362 .736 & -224.119 & -3.964 .551 \\
\hline \multirow[t]{2}{*}{ Tendência temporal } & -1.574 .452 & -592.797 & -2.101 .841 & 7.623 .589 \\
\hline & -9.330 .593 & -3.537 .587 & -1.439 .284 & -9.119 .336 \\
\hline \multirow[t]{2}{*}{ (Tendência temporal)^2 } & 2.302 .667 & 9.799 .999 & 2.994 .827 & -117.752 \\
\hline & -124.173 & -5.077 .722 & -1.881 .653 & -1.224 .701 \\
\hline \multirow[t]{2}{*}{ Constante } & 2.399 .176 & $388.1042^{*}$ & 3.352 .514 & -2.729 .849 \\
\hline & -1.647 .077 & -8.101 .017 & -2.706 .746 & -1.458 .624 \\
\hline Observações & 38,707 & 38,705 & 38,703 & 38,251 \\
\hline$R^{2}$ & 0.7630 & 0.5381 & 0.8654 & 0.8158 \\
\hline
\end{tabular}

Fonte: Elaboração própria. Nota: Erro padrão robusto entre parênteses. ${ }^{*}$ denota a significância ao nível de $5 \%$. 
Neste sentido, cabe destacar que a literatura trata que a ocorrência de desastres pode gerar impactos na saúde mental dos afetados ${ }^{9}$. Segundo Bierkens et al. (2012), a exposição ao Chumbo (Pb) causa danos ao QI em crianças em idade préescolar, evidenciando efeitos neurológicos negativos. Ha (2016) avalia a gestão de desastres como um fator relevante como forma preventiva de casos de suicídio. Já Ampuero et al. (2015) e Van Ootegem e Verhofstadt (2016) tratam dos efeitos traumáticos e pós-traumáticos do desastre ambiental e sua influência no bem-estar mental, gerando depressão e estresse. Além disso, a perspectiva sob a qual as vítimas entendem o próprio desastre influencia sua capacidade de recuperação e reconstrução, segundo Kumagai et al. (2006).

Ainda no tocante a possíveis efeitos na saúde, é possível que indicadores de ocorrência de doenças como diarreia, hepatite A e leptospirose possam evidenciar os efeitos do desastre no curto prazo, ocasionadas por microrganismos transportados pela água e que contamina poços e lavouras ${ }^{10}$. (Peixoto, 2015). Ademais, os possíveis efeitos como o aumento da incidência de certas doenças, por exemplo, febre amarela ${ }^{11}$, podem ser indicativos para estabelecimento de programas de vacinação como foi verificado nos relatórios de danos e perdas do Banco Mundial ((Mundial, 2012a); (Mundial, 2012b)). Por fim, Freitas et al. (2019) destaca a relevância do conjunto de ações imediatas e integradas do Sistema Único de Saúde (SUS) para minimização dos impactos, prevenção de riscos e danos à saúde.

\subsection{Análise sobre o Indicador Econômico}

Em relação ao indicador econômico considerado na pesquisa, vide Tabela 4 abaixo, pode-se inferir que o desastre ambiental apresenta evidências de impacto sobre o PIB municipal, referente aos municípios interceptados e limítrofes ao Rio Doce, grupos 1 e 2, bem como pelos municípios afetados pelo desastre, segundo a ANA (grupo 3). Desta forma, o PIB desses municípios foi afetado negativamente pelo desastre ocorrido em Mariana. Essa evidência justifica-se, no curto prazo, por mudanças na empregabilidade em diversos setores da economia e, possivelmente, por consequência no nível de arrecadação e dos gastos públicos. No que se refere aos municípios pertencentes ao Quadrilátero Ferrífero (grupo 4), não foi verificada evidência no tocante a efeitos após o desastre. Isso pode ter acontecido pela concentração da produção ferrífera na região, minas de ouro e manganês, que podem ter amortecido o impacto econômico nessa região no curto prazo.

\footnotetext{
${ }^{9}$ Os efeitos de saúde mental não são captados pelos casos de internações.

${ }^{10}$ Ver: https://www.em.com.br/app/noticia/gerais/2015/11/09/interna_gerais,705830/especialistasalertam-sobre-perigos-a-saude-de-quem-teve-contato-com-a.shtml (Acesso em: 20/08/2020).

${ }^{11}$ Ver: https://saude.estadao.com.br/noticias/geral,para-biologa-surto-de-febre-amarela-pode-terrelacao-com-tragedia-de-mariana, 10000100032 (Acesso em: 21/08/2020).
} 
Tabela 4. Efeitos sobre o PIB Municipal (mil reais)

\begin{tabular}{|c|c|c|c|c|}
\hline PIB Municipal & Tratado 1 & Tratado 2 & Tratado 3 & Tratado 4 \\
\hline \multirow[t]{2}{*}{ tratado 1} & $112290.1^{*}$ & & & \\
\hline & $(43212.79)$ & & & \\
\hline \multirow[t]{2}{*}{ tratado2 } & & -13782.14 & & \\
\hline & & (10936.63) & & \\
\hline \multirow[t]{2}{*}{ tratado3 } & & & $284878.7^{*}$ & \\
\hline & & & $(68915.48)$ & \\
\hline \multirow[t]{2}{*}{ tratado 4} & & & & $449973.2^{*}$ \\
\hline & & & & (1 19242.6) \\
\hline \multirow[t]{2}{*}{ Tempo } & 131656.1 & $56248.67^{*}$ & 184542 & -69775.26 \\
\hline & (72290.13) & (22110.66) & $(128788.7)$ & $(231795.2)$ \\
\hline \multirow[t]{2}{*}{ Tempo*tratado 1} & $-163019.7^{*}$ & & & \\
\hline & $(63358.87)$ & & & \\
\hline \multirow[t]{2}{*}{ Tempo*tratado2 } & & $-69556.14^{*}$ & & \\
\hline & & $(18943.16)$ & & \\
\hline \multirow[t]{2}{*}{ Tempo*tratado3 } & & & $-295185.7^{*}$ & \\
\hline & & & (119330.2) & \\
\hline \multirow[t]{2}{*}{ Tempo*tratado4 } & & & & 84421.7 \\
\hline & & & & $(289727.5)$ \\
\hline \multirow[t]{2}{*}{ Famílias Beneficiadas BF } & $65.11235^{*}$ & $17.93159^{*}$ & $64.36582^{*}$ & $325.1556^{*}$ \\
\hline & -1.368 .589 & -4.720 .457 & -3.136 .742 & -5.037 .108 \\
\hline \multirow[t]{2}{*}{$\mathrm{MG}$} & -28977.12 & $-19262.41^{*}$ & -69200.55 & 48644.7 \\
\hline & $(23336.58)$ & -6.025 .041 & $(37354.42)$ & $(47027.78)$ \\
\hline \multirow[t]{2}{*}{ ES } & -31828.33 & $63319.21^{*}$ & -165087 & -13752.86 \\
\hline & (82289.03) & $(22821.73)$ & $(159591.7)$ & $(246161.1)$ \\
\hline \multirow[t]{2}{*}{ Tendência temporal } & $122037.5^{*}$ & $45446.07^{*}$ & 160786 & $418228^{*}$ \\
\hline & $(57513.86)$ & $(17654.38)$ & $(97473.1)$ & $(212453.7)$ \\
\hline \multirow[t]{2}{*}{ (Tendência temporal)^2 } & -11266.49 & -3.162 .589 & -16088.5 & -32997.21 \\
\hline & -7.598 .493 & -2.321 .365 & $(13094.32)$ & $(27211.91)$ \\
\hline \multirow[t]{2}{*}{ Indicador - estrutura da indústria local } & $-855330.7^{*}$ & $-878561.5^{*}$ & -500624.4 & -346807.5 \\
\hline & $(179567.8)$ & $(80822.51)$ & $(327051.1)$ & $(508471.4)$ \\
\hline \multirow[t]{2}{*}{ Abertura comercial (saldo) } & $0.0007625^{*}$ & $0.0010126^{*}$ & $0.0011236^{*}$ & $0.001393^{*}$ \\
\hline & $(0.0002556)$ & $(0.0001802)$ & $(0.0002936)$ & $(0.000249)$ \\
\hline \multirow[t]{2}{*}{ № de entidades de ensino superior } & 139882.9 & $-143998.5^{*}$ & $349346.1^{*}$ & $325038.7^{*}$ \\
\hline & (82159.93) & $(24964.97)$ & $(105543.7)$ & $(122672.5)$ \\
\hline \multirow[t]{2}{*}{ Administração Pública } & $119.4874^{*}$ & $41.15092^{*}$ & $101.0546^{*}$ & -9.242 .947 \\
\hline & -4.269 .608 & -2.075 .372 & -4.594 .414 & -7.065 .642 \\
\hline
\end{tabular}


Tabela 4.Efeitos sobre o PIB Municipal (mil reais) - Continuação

\begin{tabular}{lllll}
\hline \hline PIB Municipal & Tratado 1 & Tratado 2 & Tratado 3 & Tratado 4 \\
\hline Agropecuária, extração vegetal, caça e pesca & $101.0654^{*}$ & $109.3282^{*}$ & $180.8315^{*}$ & $547.9505^{*}$ \\
& -4.519 .814 & -1.624 .867 & -6.883 .761 & -2.454 .706 \\
Comércio & -3.997 .886 & 6.168 .267 & $-143.6295^{*}$ & $-209.254^{*}$ \\
& -4.470 .866 & -1.963 .473 & -6.975 .491 & -1.062 .016 \\
Construção Civil & $-279.47^{*}$ & $286.1923^{*}$ & $-452.5787^{*}$ & $-403.5161^{*}$ \\
& -8.651 .632 & -4.505 .338 & -1.127 .411 & -1.440 .462 \\
Indústria de transformação & $243.5328^{*}$ & $181.1514^{*}$ & $253.4595^{*}$ & $230.7667^{*}$ \\
& -1.670 .794 & -849.614 & -2.104 .238 & -3.278 .054 \\
Serviços industriais de utilidade pública & $-2283.723^{*}$ & $697.0221^{*}$ & $-1857.111^{*}$ & $-1332.89^{*}$ \\
& -3.631 .326 & -1.874 .132 & $(616.41)$ & -4.025 .745 \\
Serviços & $214.5681^{*}$ & $150.0724^{*}$ & $260.0704^{*}$ & $291.8817^{*}$ \\
& -1.688 .323 & -1.127 .997 & -2.400 .287 & -4.123 .219 \\
Constante & $-315843.7^{*}$ & $-63585.55^{*}$ & $-406536.8^{*}$ & $-1466158^{*}$ \\
& $(98072.16)$ & $(30118.33)$ & $(157206.7)$ & $(359686.9)$ \\
\hline Observações & 38,936 & 38,934 & 38,932 & 38,934 \\
$R^{2}$ & 0.9148 & 0.8274 & 0.9674 & 0.9939 \\
\hline \hline
\end{tabular}

Fonte: Elaboração própria. Nota: Erro padrão robusto entre parênteses. * denota a significância ao nivel de $5 \%$.

Tais resultados corroboram Simonato et al. (2018), que observou um efeito espraiamento relevante dos impactos negativos nos municípios mineiros ao longo do Rio Doce, transmitidos principalmente pelas compras e vendas regionais, além dos efeitos negativos no emprego. Vale destacar que, segundo Castro e Almeida (2019), no tocante à produção extrativa mineral, o desastre de Mariana impactou negativamente ambos os estados do Espírito Santo e de Minas Gerais; no entanto, os autores evidenciam que ES foi o estado que sofreu maiores efeitos do desastre, pois também sofreu impactos na produção industrial. Além disso, Sales e Rocha (2020) verificaram nos resultados econômicos impacto negativo no PIB municipal $(-5,4 \%)$, com destaque para o efeito negativo sobre o setor industrial (-13,8\%). Ademais, Martini e Gallo (2020) através da metodologia de controle sintético observaram que os desastres naturais impactaram negativamente, com efeitos prolongados de dois anos para o PIB e um ano para o PIB per capita dos municípios afetados. Tal efeito no PIB per capita também foi observado por Oliveira (2017) que a partir do modelo de painel dinâmico baseado no sistema de métodos dos momentos generalizados (GMM) verificou que o crescimento econômico dos municípios cearenses é negativamente afetado pelos desastres naturais ocorridos no Ceará, com maior impacto para o setor agrícola. 


\section{Considerações Finais}

O estudo realiza uma análise quantitativa do desastre ambiental provocado pelo rompimento da barragem de Fundão da mineradora Samarco em Mariana - MG, em 05 de novembro de 2015, e, para identificar os efeitos locais, utilizam-se como estratégia de identificação os municípios que foram afetados, direta e indiretamente, pelo desastre ambiental, uma vez que o rompimento da barragem despejou rejeitos no Rio Doce. Vale ressaltar que o desastre de Mariana pode ter provocado diversos impactos socioeconômicos na região, de modo que, além dos impactos nos indicadores econômicos, a análise no setor da saúde e na educação também deve ser, de fato, realizada.

Em função disso, este estudo visa contribuir com análises por meio do modelo DD combinado com PSM, utilizando dados municipais de diversas fontes (IBGE, INEP, RAIS, MDS, DATASUS) que foram agregados a partir do código de identificação municipal do IBGE, para captar possíveis efeitos sobre indicadores de educação (medidas de fluxo escolar como, aprovação, reprovação e abandono), saúde (número de internações) e econômicos (PIB Municipal).

Em relação aos resultados, verificou-se que os municípios respondem de forma distinta aos efeitos de curto prazo do rompimento da barragem e do desastre ambiental em função da onda de rejeitos e detritos que percorreram os cursos do córrego Santarém e dos Rios Gualaxo Norte e do Carmo até alcançar o Rio Doce, seguindo seu curso até a sua foz em Linhares, litoral do Espírito Santo. Mesmo assim, pode-se dizer que os resultados analisados (saúde, educação e socioeconômicos) estão, em geral, em consonância com a literatura.

Acredita-se que alguns impactos ambientais ainda não são conhecidos, uma vez que os efeitos contemplam apenas indicadores que podem ser quantificados no curto prazo. Sendo assim, a magnitude e a extensão das perdas ainda não podem ser identificadas e quantificadas por conta da ausência de compreensão dos dados das condições ecológicas das áreas antes do dano, dado o conhecimento limitado sobre os ecossistemas. Os efeitos sobre a saúde nos municípios que utilizam as águas dos rios atingidos pelos rejeitos de mineração também podem ser identificados no médio e longo prazo. Portanto, além dos efeitos estimados e aqui apresentados, fazse necessário monitorar os ecossistemas durante um longo período para identificar a magnitude e a extensão dos danos associados ao desastre ambiental de Mariana MG.

\section{Referências}

ALMG (2016). Relatório Final. Assembleia Legislativa do Estado de Minas Gerais. Comissão Extraordinária das Barragens.

Ampuero, D., Goldswosthy, S., Delgado, L. E., e Miranda J, C. (2015). Using mental 
well-being impact assessment to understand factors influencing well-being after a disaster. Impact Assessment and Project Appraisal, 33(3):184-194.

ANA (2016). Encarte especial sobre a bacia do Rio Doce-Rompimento da barragem em Mariana/MG. Conjuntura dos Recursos Hidricos no Brasil-Informe 2015, Página 50. Agência Nacional de Águas (ANA). Brasilia-DF, Brazil.

Bierkens, J., Buekers, J., Van Holderbeke, M., e Torfs, R. (2012). Health impact assessment and monetary valuation of iq loss in pre-school children due to lead exposure through locally produced food. Science of the Total Environment, 414:9097.

Carrillo, B., Da Mata, D., Emanuel, L., Lopes, D., e Sampaio, B. (2020). Avoidable environmental disasters and infant health: Evidence from a mining dam collapse in brazil. Health economics, 29(12):1786-1794.

Castro, L. S. e Almeida, E. S. (2019). Desastres e desempenho econômico: avaliação do impacto do rompimento da barragem de mariana. Geosul, 34(70):406-429.

FEAM (2016). Inventário de Barragem do Estado de Minas Gerais FEAM. Fundação Estadual do Meio Ambiente. Secretaria de Meio Ambiente e Desenvolvimento Sustentável. Governo de Minas Gerais.

Freitas, C. M. d., Barcellos, C., Asmus, C. I. R. F., Silva, M. A. d., e Xavier, D. R. (2019). Da Samarco em Mariana à Vale em Brumadinho: desastres em barragens de mineração e Saúde Coletiva. Cadernos de Saúde Pública, 35(5).

Ha, K.-M. (2016). Managing rumor, looting, and suicide not as breaking news but as community disaster culture. Impact Assessment and Project Appraisal, 34(3):267270.

Heckman, J. J., Ichimura, H., e Todd, P. E. (1997). Matching as an econometric evaluation estimator: Evidence from evaluating a job training programme. The review of economic studies, 64(4):605-654.

IBAMA (2015). Laudo Técnico Preliminar: Impactos ambientais decorrentes do desastre envolvendo o rompimento da barragem de Fundão, em Mariana, Minas Gerais. Instituto Brasileiro do Meio Ambiente e dos Recursos Naturais Renováveis (IBAMA). Ministério do Meio Ambiente Brasília.

Kumagai, Y., Edwards, J., e Carroll, M. S. (2006). Why are natural disasters not "natural" for victims? Environmental Impact Assessment Review, 26(1):106-119.

Lacaz, F. A. d. C., Porto, M. F. d. S., e Pinheiro, T. M. M. (2017). Tragédias brasileiras contemporâneas: o caso do rompimento da barragem de rejeitos de Fundão/Samarco. Revista Brasileira de Saúde Ocupacional, 42:1-12. 
Martini, R. A. e Gallo, M. E. C. (2020). Impactos Econômicos de Desastres Naturais nos Municípios Brasileiros e a Focalização do Programa BNDES PER. In: 48 Encontro Nacional de Economia - Anpec.

Menezes Filho, N. A., Peixoto, B., Xavier, P. C. C. d., Lima, L., Foguel, M. N., e de, B. R. P. (2017). Avaliação Econômica de Projetos Sociais. Fundação Itaú Social, São Paulo, 3 edition.

Milanez, B. e Losekann, C. (2016). Desastre no Vale do Rio Doce: antecedentes, impactos e ações sobre a destruição. Letra e Imagem Editora e Produções LTDA.

Mrejen, M., Perelman, J., e Machado, D. C. (2020). Environmental disasters and birth outcomes: Impact of a tailings dam breakage in brazil. Social Science \& Medicine, 250:112868.

Mundial, B. (2012a). Avaliação de perdas e danos: Inundações bruscas em santa catarina-novembro de 2008. Brasília: BM, Página 14-15.

Mundial, B. (2012b). Avaliação de perdas e danos: Inundações bruscas em santa catarina-novembro de 2010. Brasília: BM, Página 14-15.

Niquito, T., Pozzobona, F., Halmenschlager, V., e Ribeiro, F. G. (2019). Desastres Tecnológicos e Impacto Econômico para uma economia em Desenvolvimento:Evidências para o Brasil. In: 47 Encontro Nacional de Economia - Anpec.

Oliveira, V. H. d. (2017). Natural Disasters and Economic Growth in the Northeastern Brazil:Evidence from Municipal Economies of the State of Ceará. Texto para discussão, IPECE.

Peixoto, M. (2015). Especialistas alertam sobre perigos à saúde de quem teve contato com a lama em Mariana. Estado de Minas. Minas Gerais. 09 de novembro de 2015.

Queiroz, H. M., Ferreira, Tiago O.and Barcellos, D., Nóbrega, G. N., Antelo, J., Otero, X. L., e Bernardino, A. F. (2021). From sinks to sources:The role of Fe oxyhydroxide transformations on phosphorus dynamics in estuarine soils. Journal of Environmental Management, 278:111575.

Rosenbaum, P. R. e Rubin, D. B. (1983). The central role of the propensity score in observational studies for causal effects. Biometrika, 70(1):41-55.

Saito, S. (2008). Desastres naturais: conceitos básicos. i escuela de primavera sobre soluciones especiales para el manejo del desastres naturales y repuestas de emergências-inundaciones. Santa Maria: INPE-CRS.

Sales, N. M. e Rocha, R. B. d. (2020). Environmental Disaster:Economic and Health Outcomes. Dissertação de Mestrado, Universidade Federal do Rio de Janeiro (UFRJ).

Simonato, T. C., Domingues, E. P., e Magalhães, A. S. (2018). Projeção dos impactos econômicos regionais do desastre de Mariana_MG. In: 46 Encontro Nacional de Economia - Anpec. 
Torres, J. P. M., Souza, J., Padilha, J., Oliveira, G., e Paiva, T. (2017). Contaminação por metais pesados na água utilizada por agricultores familiares na região do rio doce. Texto para discussão, Greenpeace and Universidade Federal do Rio de Janeiro.

United Nations Office for Disaster Risk Reduction UNDRR (2009). Global assessment report on disaster risk reduction. Texto para discussão, Nações Unidas.

Van Ootegem, L. e Verhofstadt, E. (2016). Well-being, life satisfaction and capabilities of flood disaster victims. Environmental Impact Assessment Review, 57:134-138.

(G) Este artigo está licenciado com uma CC BY 4.0 license.

\section{Agradecimentos}

Os autores agradecem aos comentários e sugestões de Ivan Castelar, Kamila Viera Mendonça, Rosália Kjaer, Wesley Leitão e dos pareceristas da Revista Brasileira de Estudos Regionais e Urbanos (RBERU). Ressaltanto que erros e omissões são de responsabilidade do autores. O presente trabalho foi realizado com apoio da Coordenação de Aperfeiçoamento de Pessoal de Nivel Superior - Brasil (CAPES) - Código de Financiamento 001.

\section{Anexo}

Gráficos dos Escore de Propensão por grupos de Tratados (1 a 4) e por indicadores de resultados. 
Gráfico 1 -Tratado 1, Abandono

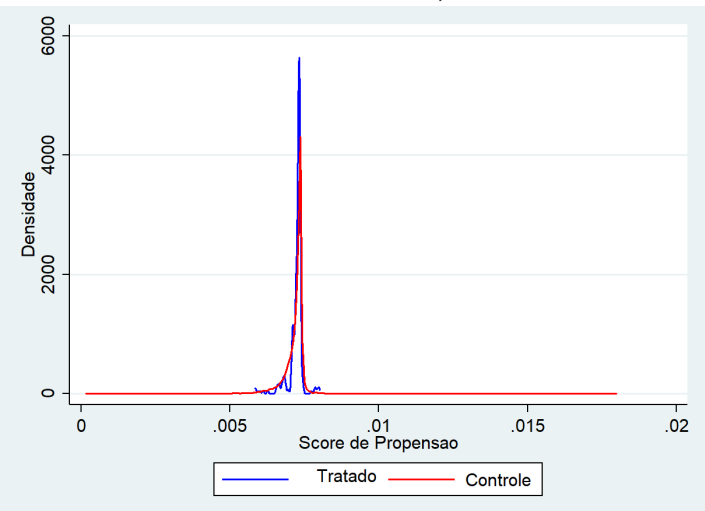

Gráfico 3 -Tratado 1, Reprovação

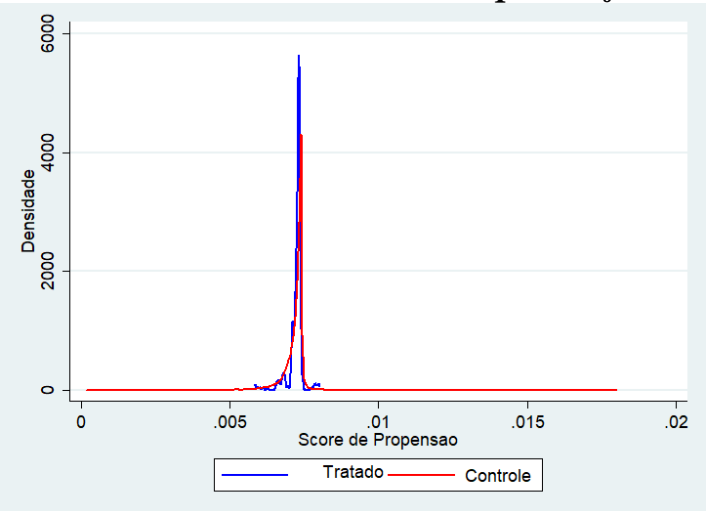

Gráfico 5 -Tratado 1, Economia

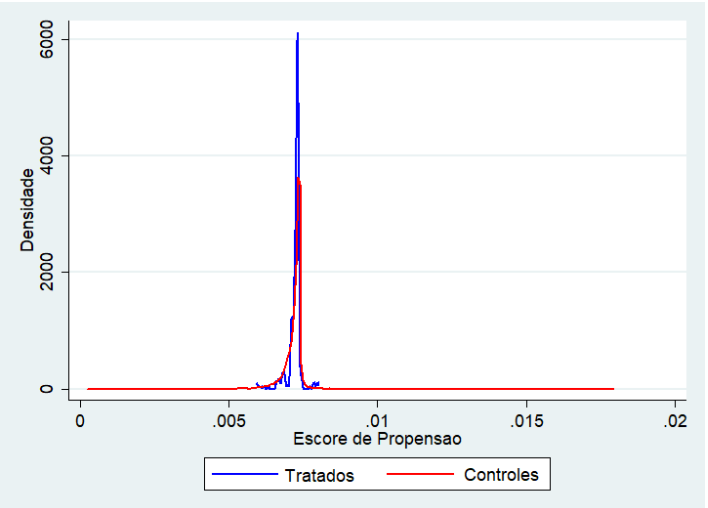

Gráfico 7 - Tratado 2, Aprovação

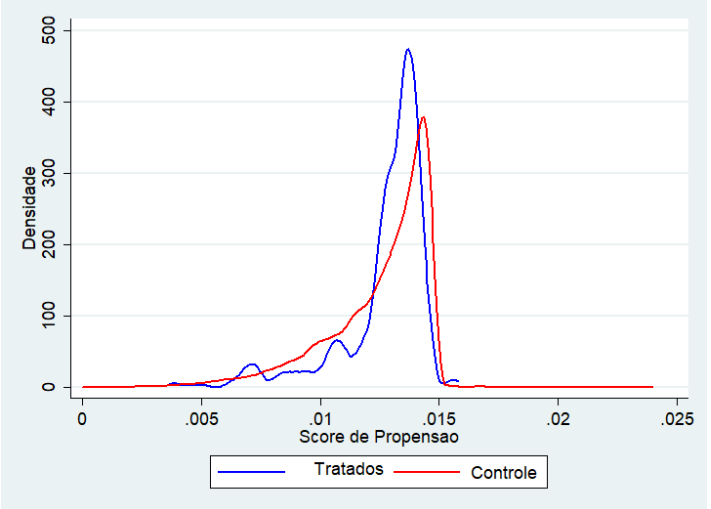

Gráfico 2 - Tratado 1, Aprovação

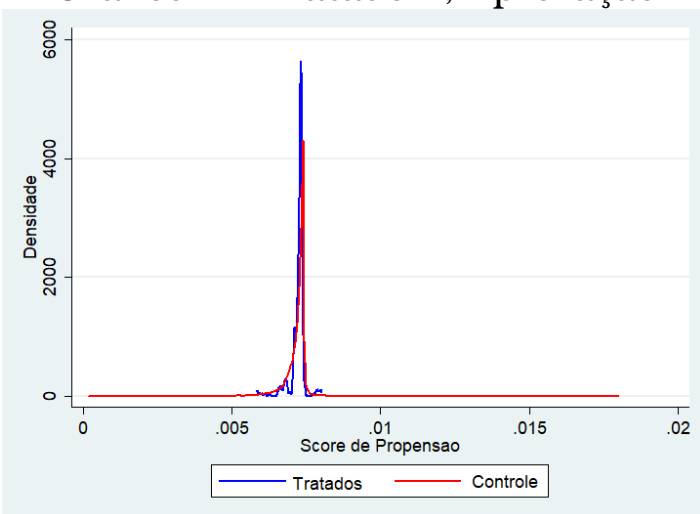

Gráfico 4 - Tratado 1, Saúde

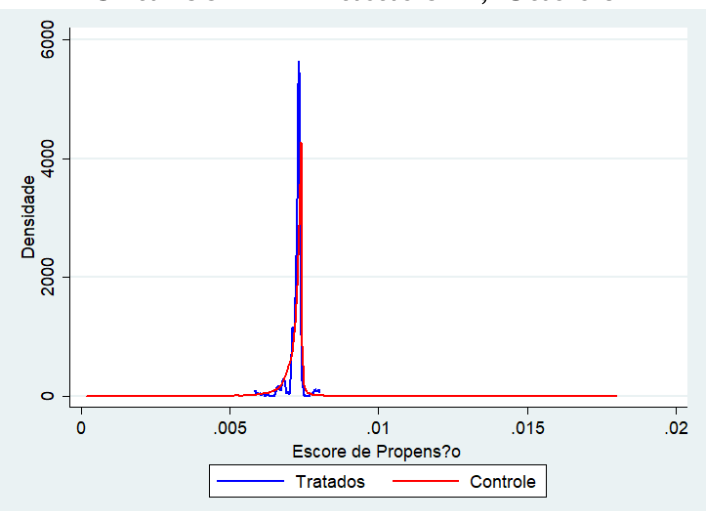

Gráfico 6 -Tratado 2, Abandono

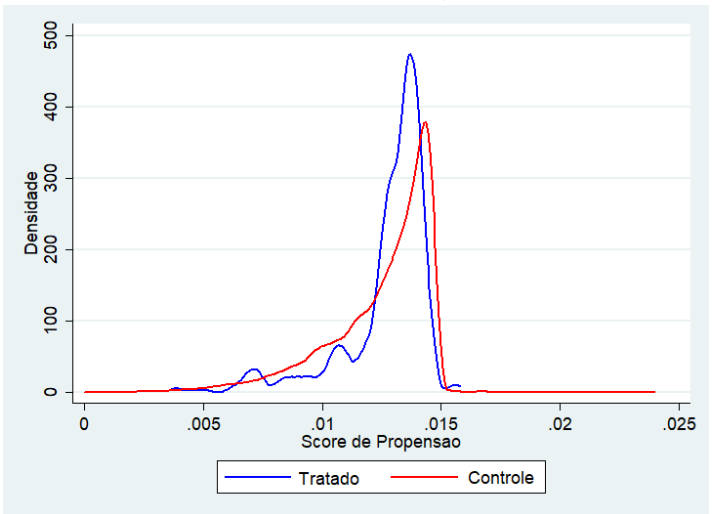

Gráfico 8 -Tratado 2, Reprovação

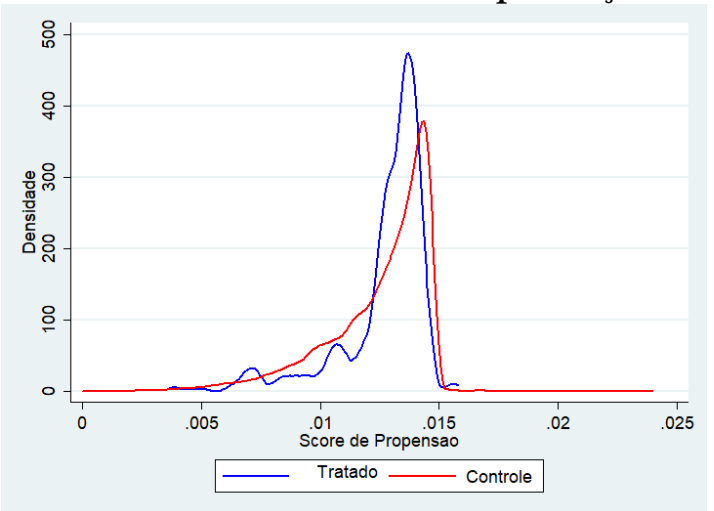


Gráfico 9 - Tratado 2, Saúde

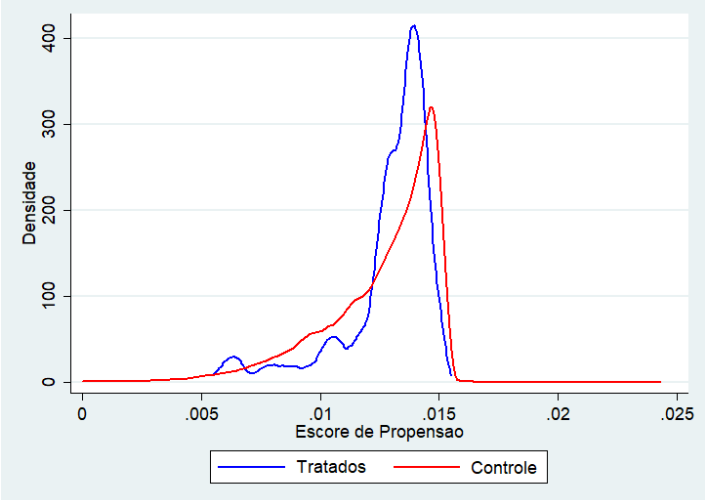

Gráfico 11 - Tratado 3, Abandono

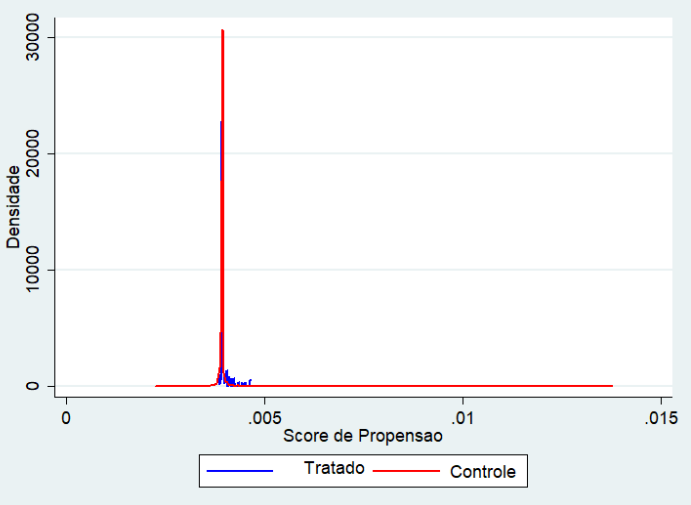

Gráfico 13 - Tratado 3, Reprovação



Gráfico 15 - Tratado 3, Economia

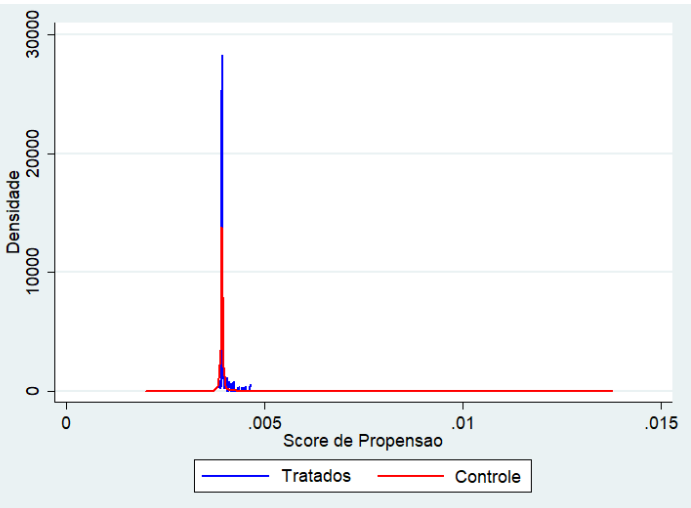

Gráfico 10 - Tratado 2, Economia

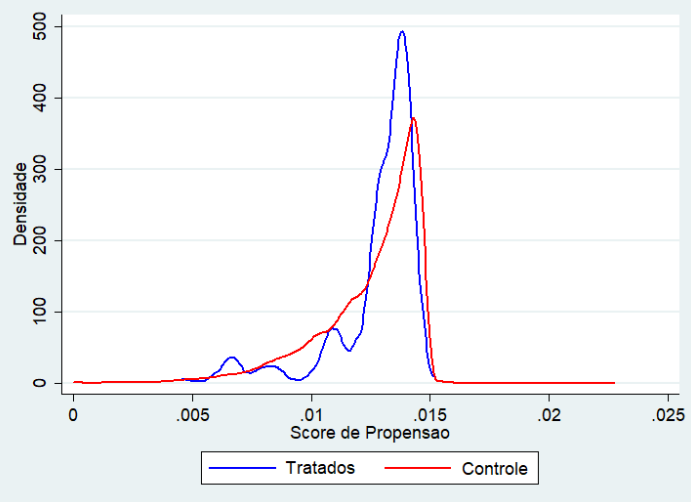

Gráfico 12 - Tratado 3, Aprovação



Gráfico 14 - Tratado 3, Saúde

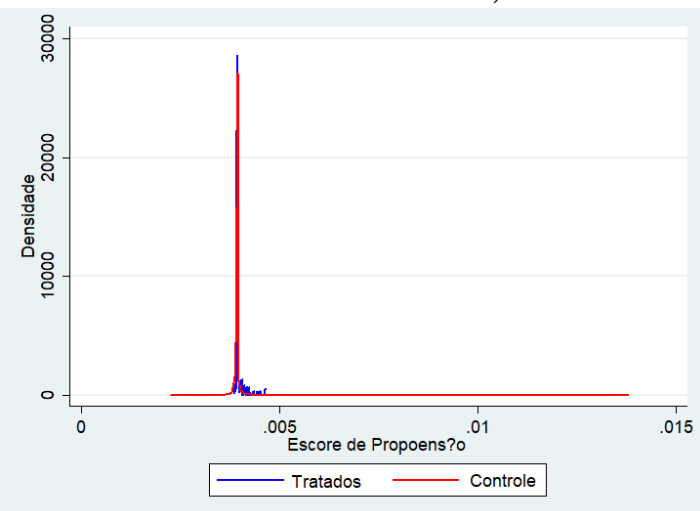

Gráfico 16 - Tratado 4, Abandono

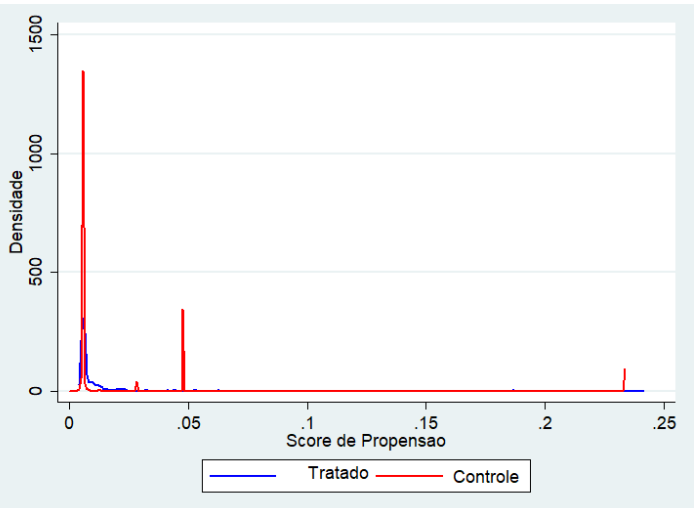


Gráfico 17 - Tratado 4, Aprovação

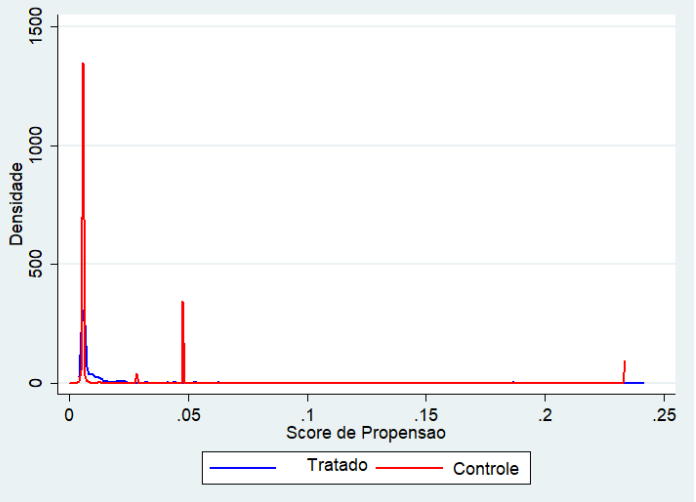

Gráfico 19 - Tratado 4, Saúde



Fonte: Elaboração própria.
Gráfico 18 - Tratado 4, Reprovação

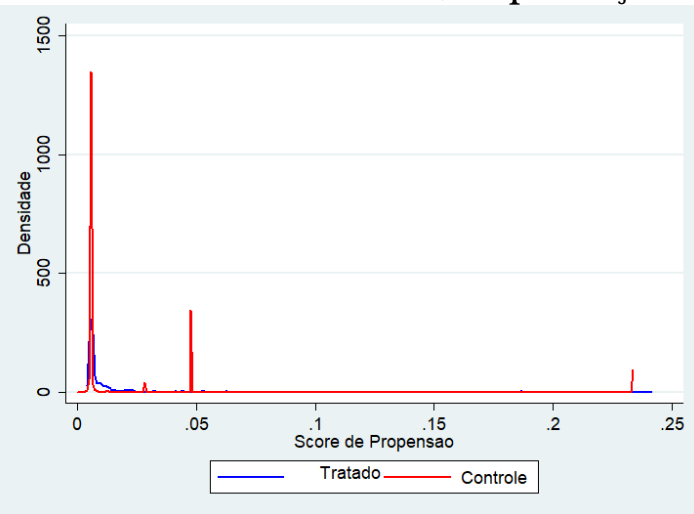

Gráfico 20 - Tratado 4, Economia

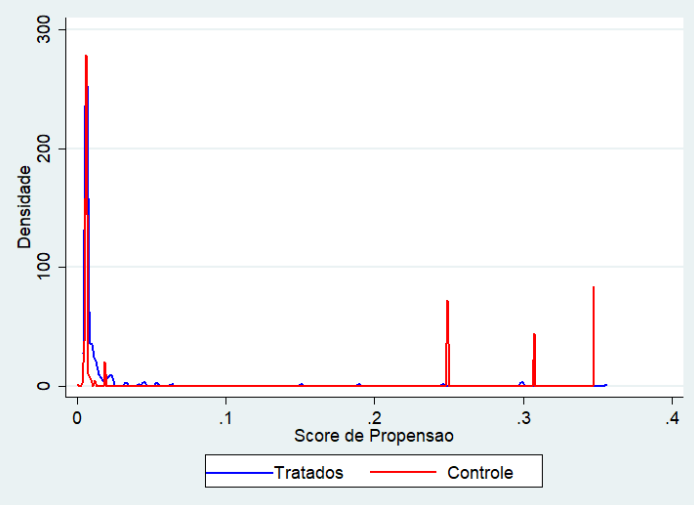

